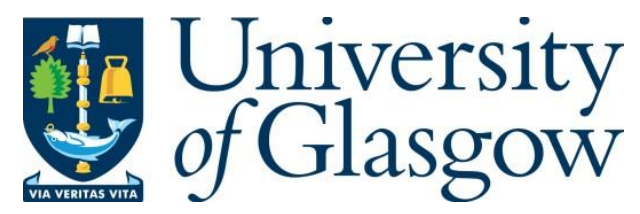

Mitchell, K. R. et al. (2017) Authors' reply re: painful sex (dyspareunia) in women: prevalence and associated factors in a British population probability survey. BJOG: An International Journal of Obstetrics and Gynaecology, 124(11), pp. 1789-1790.

There may be differences between this version and the published version. You are advised to consult the publisher's version if you wish to cite from it.

This is the peer reviewed version of the following article: Mitchell, K. R. et al. (2017) Authors' reply re: painful sex (dyspareunia) in women: prevalence and associated factors in a British population probability survey. BJOG: An

International Journal of Obstetrics and Gynaecology, 124(11), pp. 1789-1790, which has been published in final form at http://dx.doi.org/10.1111/1471-

$\underline{0528.14626}$. This article may be used for non-commercial purposes in accordance with Wiley Terms and Conditions for Self-Archiving.

$\underline{\text { http://eprints.gla.ac.uk/148686/ }}$

Deposited on: 9 October 2017

Enlighten - Research publications by members of the University of Glasgow http://eprints.gla.ac.uk 


\section{Re: 'Painful sex (dyspareunia) in women: prevalence and associated factors in a British population probability survey’}

Sir,

We thank Matthes and Zucca-Matthes for their comments on our paper ${ }^{1,2}$ and agree with them that this is a neglected aspect of women's health that requires greater focus on clinical outcomes through robust research. The aim of our prevalence study was to outline the scale of the problem at a population level. The data come from the National Survey of Sexual Attitudes and Lifestyles; they are broad in scope and do not permit detailed investigation of clinical subgroups. Obtaining clinically sufficient information in the context of a population survey is rarely feasible due to small numbers in subgroups and the complexity of information required. In addition we cannot make the assumption that the deep and superficial dyspareunia framework correlates to different pathologies as the experience of painful sex is complex and is dependent on a variety of physical reasons (e.g. lubrication, menopausal state, skin disease) as well as psychosexual factors. Matthes and ZuccaMatthes suggest that we may have underestimated the prevalence of painful sex by including women who might be having sex exclusively without vaginal penetration. They suggest that disproportion between penis and vagina size may be relevant and that this may be true for selected subgroups of patients (e.g. post-hysterectomy or women receiving vaginal radiotherapy) where is there is limited capacity and compromised function. However, for the majority of women without organic pathology, it remains unclear whether there is a correlation between penis size, vaginal capacity and overall experience. Having highlighted the problem in our paper, we would welcome clinical teams to support research focusing on defining and improving clinical outcomes for these women.

\section{References}

1 Matthes ACS, Zucca-Matthes G. Re: Painful sex (dyspareunia) in women: prevalence and associated factors in a British population probability survey. Dyspareunia is a global public health problem!. BJOG 2017;124:

2 Mitchell KR, Geary R, Graham CA, Datta J, Wellings K, Sonnenberg P, et al. Painful sex (dyspareunia) in women: prevalence and associated factors in a British populationprobability survey. BJOG, January 2017; DOI: 10.1111/1471-0528.14518.

\section{Authors}

Kirstin R Mitchell, ${ }^{1,2}$ Rebecca Geary, ${ }^{3}$ Cynthia A Graham, ${ }^{4}$ Jessica Datta, ${ }^{1}$ Kaye Wellings, ${ }^{1}$ Pam Sonnenberg, ${ }^{3}$ Nigel Field, ${ }^{3}$ David Nunns, ${ }^{5}$ JohnBancroft, ${ }^{6}$ Kyle G Jones, ${ }^{3}$ Anne M Johnson, ${ }^{3}$ \& Catherine $\mathrm{H}$ Mercer, ${ }^{3}$

1 Centre for Sexual and Reproductive Health Research, Department of Social and Environmental Health Research, London School of Hygiene and Tropical Medicine, London, UK

$2 \mathrm{MRC/CSO}$ Social and Public Health Sciences Unit, University of Glasgow, Glasgow, UK

3 Centre for Sexual Health and HIV Research, Research Department of Infection \& Population Health, University College London, London, UK

4 Centre for Sexual Health Research, Department of Psychology, University of Southampton, Southampton, UK

5 Department of Gynaecology, Nottingham University Hospitals NHS Trust, Nottingham, UK

6 Department of Psychiatry, University of Oxford, Oxford, UK 